\title{
Impaired intrarenal dopamine production following intravenous sodium chloride infusion in Type 1 (insulin-dependent) diabetes mellitus
}

\author{
P.Stenvinkel ${ }^{1}$, A.K. Saggar-Malik ${ }^{1}$, H. Wahrenberg ${ }^{2}$, U. Diczfalusy $^{3}$, J. Bolinder $^{2}$ and A. Alvestrand ${ }^{1}$ \\ Departments of ${ }^{1}$ Renal Medicine, ${ }^{2}$ Medicine, and \\ ${ }^{3}$ Clinical Chemistry, Karolinska Institute, Huddinge University Hospital, Stockholm, Sweden
}

\begin{abstract}
Summary. Type 1 (insulin-dependent) diabetes mellitus is characterized by impaired sodium excretion following $\mathrm{NaCl}$ infusion. To investigate the possible role of dopamine in the impaired natriuresis in diabetes, intrarenal sodium handling, sodium excretion and urinary dopamine output, reflecting intrarenal dopamine formation, were studied following a $2 \mathrm{~h} 0.9 \% \mathrm{NaCl}$ infusion $(25 \mathrm{ml} / \mathrm{kg}$ ) in eight diabetic patients and nine control subjects. The increase in sodium excretion in response to $\mathrm{NaCl}$ infusion was significantly $(p<0.01)$ reduced in diabetic patients $(19 \pm 7 \%)$ as compared with control subjects $(46 \pm 8 \%)$. Fractional proximal tubular sodium reabsorption (determined by lithium clearance) decreased in the control group $(p<0.01)$ following $\mathrm{NaCl}$ infusion but not in the diabetic group. Fractional distal tubular reabsorption decreased similarly in both groups. In response to $\mathrm{NaCl}$ urinary dopamine excretion increased by approximately $15 \%(p<0.01)$ in the control group but did not change in the diabetic group. The mean urinary dopamine excretion above basal was significantly greater
\end{abstract}

in the control group $(8.4 \pm 2.1 \mathrm{nmol} / \mathrm{h})$ than in the diabetic group $(-2.2 \pm 2.1 \mathrm{nmol} / \mathrm{h} ; p<0.01)$. The urinary sodium/dopamine excretion ratio did not differ significantly between the two groups in the basal state or following $\mathrm{NaCl}$. Baseline plasma levels of atrial natriuretic peptide did not differ between control and diabetic patients. In the control group atrial natriuretic peptide levels increased significantly $(p<0.01)$ in response to $\mathrm{NaCl}$ whereas atrial natriuretic peptide levels did not change in the diabetic group. The results of this study show that patients with Type 1 diabetes have a blunted natriuresis in response to isotonic $\mathrm{NaCl}$. This abnormality seems mainly to be due to impaired inhibition of proximal tubular sodium reabsorption, which may be the result of defective intrarenal dopamine mobilisation.

Key words: Type 1 (insulin-dependent) diabetes mellitus, sodium retention, dopamine, atrial natriuretic peptide, proximal tubule.
A well recognized feature of Type 1 (insulin-dependent) diabetes mellitus is the tendency to sodium retention. Several studies have shown that patients with metabolically stable Type 1 diabetes have a $10-15 \%$ increase in total exchangeable sodium $[1,2]$. It has also been documented that diabetic subjects have an impaired ability to excrete sodium following intravenous salt loading [3-5] or water immersion [6] and it has been suggested that increased tubular sodium reabsorption is an early functional change in the diabetic kidney [6]. The mechanism(s) of these phenomena remain unclear, but hyperinsulinaemia $[4,7-9]$ and atrial natriuretic peptide (ANP) abnormalities in hormonal action and secretion [4] have been discussed as contributing factors.

Among other putative factors the role of endogenous intrarenal dopamine as a locally acting natriuretic and vasodilatory agent has attracted increasing attention in the last decade [10]. Filtered L-dopa is decarboxyl- ated to dopamine by L-dopa-decarboxylase, an enzyme which is present in abundance in the proximal tubular cells [11]. Dopamine, by rapid and reversible inhibition of $\mathrm{Na}^{+}-\mathrm{K}^{+}$-ATPase in the proximal tubule, thereby causes natriuresis [12]. It has recently been clearly demonstrated that all of the urinary excretion of endogenous dopamine is accounted for by uptake and decarboxylation of circulating endogenous L-dopa in proximal tubular cells [13].

In the present study the acute effect of intravenous $\mathrm{NaCl}$ infusion on sodium excretion, urinary dopamine output and renal haemodynamics was studied in patients with Type 1 diabetes. As compared with control subjects, diabetic patients showed delayed sodium excretion which was associated with defective urinary dopamine excretion, suggesting that impaired renal dopamine formation may be a contributing factor to sodium retention in Type 1 diabetes. 


\section{Subjects and methods}

\section{Subjects}

Eight male patients with Type 1 diabetes, aged $27 \pm 3$ (SD) years (range 22-30 years), with a mean duration of diabetes of $9 \pm 7$ (SD) years (range $4-25$ years) were studied. They were all normotensive according to WHO standards. Their systolic, diastolic, and mean arterial blood pressures were $121 \pm 4 \mathrm{~mm} \mathrm{Hg}, 85 \pm 3 \mathrm{~mm} \mathrm{Hg}$ and $97 \pm 3 \mathrm{~mm} \mathrm{Hg}$, respectively. Their $\mathrm{HbA}_{1 \mathrm{c}}$ levels ranged between 5.3 and $8.5 \%$ (mean $7.3 \pm 0.5 \%$ ). Body mass index (BMI) was $24.2 \pm 1.1$ (body weight $/$ length ${ }^{2} ; \mathrm{kg} / \mathrm{m}^{2}$ ). No patient was on medication other than s.c. insulin ( $58 \pm 5 \mathrm{U} /$ day) and none had any evidence of neuropathy, retinopathy or albumin excretion above $1 \mathrm{mg} / \mathrm{h}$. Nine healthy, normotensive males aged $33 \pm 1$ (SD) years (range 31-40 years) were studied as control subjects. Systolic (114 $\pm 2 \mathrm{~mm} \mathrm{Hg})$, diastolic $(74 \pm 2 \mathrm{~mm} \mathrm{Hg})$, and mean arterial blood pressures $(87 \pm 2 \mathrm{~mm} \mathrm{Hg})$ were slightly, but significantly lower $(p<0.05)$ in the control subjects than in the diabetic patients. BMI in the control group $\left(23.0 \pm 0.7 \mathrm{~kg} / \mathrm{m}^{2}\right)$ was not significantly different from that in the diabetic group. None of the control subjects were on any medication. All subjects were recommended to continue their usual diets and were maintained on an ad libitum sodium and protein diet.

\section{Study protocol}

The diabetic patients were admitted to the ward on the day prior to the investigation and were withdrawn from s.c. intermediate-acting insulin at least $24 \mathrm{~h}$ and short-acting insulin at least $15 \mathrm{~h}$ before the study period. At 17.00 hours an intravenous infusion of soluble insulin (Actrapid Human Novo A/S, Bagsvaerd, Denmark) was started, and the infusion rate was adjusted by frequent determinations of blood glucose for the purpose of maintaining stable blood glucose between 4 to $6 \mathrm{mmol} / 1$ during the night and throughout the study. All subjects received $16.2 \mathrm{mmol}$ of lithium, as lithium carbonate, orally the evening before the clearance study and all subjects fasted overnight. On the morning of investigation the subjects drank $500 \mathrm{ml}$ of tap water. At 08.00 hours infusions of $20 \%$ para-amino hippuric acid (PAH; $0.2 \mathrm{ml} / \mathrm{kg}$ body weight; rate, $0.5 \mathrm{ml} / \mathrm{min}$ ) and $25 \%$ inulin (Inutest, $0.2 \mathrm{ml} / \mathrm{kg}$ body weight; rate, $0.5 \mathrm{ml} / \mathrm{min}$ ) were started. After an equilibration period of one hour timed urine collections were started. To ensure adequate diuresis $300 \mathrm{ml}$ of tap-water was given orally each hour. During the study period the subjects were in the supine position except when voiding urine. The subjects voided urine hourly and urine samples were analysed for inulin, $\mathrm{PAH}$, lithium (Li), dopamine, sodium $(\mathrm{Na})$ and potassium $(\mathrm{K})$. Blood samples for inulin, $\mathrm{PAH}$, lithium, atrial natriuretic peptide (ANP), renin, blood glucose, haematocrit, $\mathrm{Na}$ and $\mathrm{K}$ were taken after each clearance period. After a basal one-hour clearance period an infusion of $0.9 \% \mathrm{NaCl}$ ( $154 \mathrm{mmol} / \mathrm{l})$ was started and given for $2 \mathrm{~h}$ at a rate of $25 \mathrm{ml} / \mathrm{kg}$ body weight. The subjects were then observed for a further $2 \mathrm{~h}$ with hourly blood and urine sampling. All subjects gave informed consent and approval was obtained from the Local Ethical Committee.

\section{Calculations and assay methods}

Mean arterial pressure was calculated as diastolic blood pressure + one third of the pulse pressure. Sodium $\left(\mathrm{C}_{\mathrm{Na}}\right)$, inulin $\left(\mathrm{C}_{\mathrm{In}}\right)$ and $\mathrm{li}-$ thium $\left(\mathrm{C}_{\mathrm{Li}}\right)$ clearance were calculated according to the conventional formula. The mean of the inulin, $\mathrm{PAH}$ and $\mathrm{Na}$ values, respectively, at the beginning and end of each clearance period was used for clearance calculations. Lithium clearance was performed in accordance with the method described by Thomsen [14] which is based on the assumption that lithium is reabsorbed in the proximal tubule in parallel with sodium and water and that it is neither secreted nor reabsorbed beyond the proximal tubule. Hence the fractional proximal tubular reabsorption (FPR) of sodium was calculated as $1-\left(\mathrm{C}_{\mathrm{Li}} / \mathrm{C}_{\mathrm{Ln}}\right)$ and the fractional distal tubular (FDR) sodium reabsorption as $1-\left(\mathrm{C}_{\mathrm{Na} a} / \mathrm{C}_{\mathrm{L}}\right)$. Urinary sodium and urinary dopamine were measured as $\mathrm{mmol} / \mathrm{h}$ and $\mathrm{nmol} / \mathrm{h}$, respectively.
Urinary dopamine were extracted essentially as described in [15] except that $0.1 \mathrm{~mol} / \mathrm{l}$ perchloric acid was used instead of $1 \mathrm{~mol} / \mathrm{l}$ acetic acid for the elution of adsorbed dopamine from alumina. In addition, alfa-methyldopamine was used as internal standard instead of 3,4-dihydroxy-bensylamine. Dopamine were analysed by high performance liquid chromatography with electrochemical detection. The chromatographic system consisted of a LDC Constametric III pump, a cation exchange column (Nucleosil $10 \mathrm{SA}$, $25 \mathrm{~cm} \times 4.6 \mathrm{~cm}$ ) and a BAS amperometric detector model $\mathrm{LC} 4 \mathrm{~b} / \mathrm{CC} 4$. The mobile phase was a citrate-acetate buffer, $\mathrm{pH} 5.2$ as previousty described [16]. The flow rate was $2.5 \mathrm{ml} / \mathrm{min}$ and the catecholamine concentration were calculated from peak height ratios (sample/internal standard). Specific radioimmunoassay techniques were used to analyse ANP as previously described [17] and plasma insulin [18]. Plasma renin activity was analysed with a commercial kit (Phadebas angiotensin-I test, OY Medix, Helsinki, Finland). Serum and urinary concentrations of lithium were measured by atomic absorption (Modell IL 750) according to the method previously described by Amidsen [19] with the exception that proteins was precipitated with $\mathrm{HNO}_{3}$. To correct for the precipitation of protein serum lithium concentrations was multiplied by a factor of 0.965 . Determinations of blood glucose, haematocrit, Na and K were carried out in the Department of Clinical Chemistry, Huddinge Hospital, using routine methods.

\section{Statistical analysis}

Unless stated otherwise, all data are given as means \pm SEM. Nonparametric statistics were applied. The Mann-Whitney U test was used to test differences between diabetic patients and control subjects. The Friedman two-way analysis of ranks and the Wilcoxon matched-pairs signed-ranks test were applied to test changes from basal values. Correlations between variables were tested with Spearman's rank correlation. The null hypothesis was rejected with $p$-values less than 0.05 .

\section{Results}

Mean plasma blood glucose levels did not differ between the two groups at the start of the $\mathrm{NaCl}$ infusion (diabetes: $4.7 \pm 0.4 \mathrm{mmol} / \mathrm{l}$; control $4.0 \pm 0.1 \mathrm{mmol} / \mathrm{l}$ ) and were kept constant throughout the study in both groups. There was no glucose detectable in urine at any time point during the study period in either group. In the diabetic group mean plasma insulin levels $(\mu \mathrm{U} / \mathrm{ml})$ were $26.9 \pm 4.9$ in the basal period, $22.7 \pm 5.0$ after $\mathrm{NaCl}$ and $18.1 \pm 3.82 \mathrm{~h}$ after the $\mathrm{NaCl}$ load. The corresponding plasma insulin levels in the control group were $6.4 \pm 0.9,3.9 \pm 0.3$ and $4.4 \pm 0.4 \mu \mathrm{U} / \mathrm{ml}$, respectively. There was a significant and comparable fall in haematocrit in response to $\mathrm{NaCl}$ in both groups. Urine flow rate was $7.2 \pm 0.4 \mathrm{ml} / \mathrm{min}$ in the control group and $7.9 \pm 0.5 \mathrm{ml} / \mathrm{min}$ in the diabetic group.

The haemodynamic parameters are presented in Table 1. In the control subjects glomerular filtration rate (GFR) (estimated by inulin clearance) decreased by approximately $12 \% \quad(p<0.05)$ following $\mathrm{NaCl}$ infusion, whereas GFR remained constant in the diabetic subjects. In both groups there was a transient fall in filtration fraction. The plasma renin activity did not differ significantly between the two groups in the basal state or following $\mathrm{NaCl}$ infusion (Table 1). Similarly there were no differences between the two groups with regard to plasma levels of ANP in the basal state. However, while plasma levels of ANP levels increased significantly in the control group following $\mathrm{NaCl}$ infusion, ANP levels in the diabetic group did not change (Table 1). 
Table 1. Renal haemodynamic parameters in the basal and the 1st to 4 th hour clearance periods in control and diabetic subjects

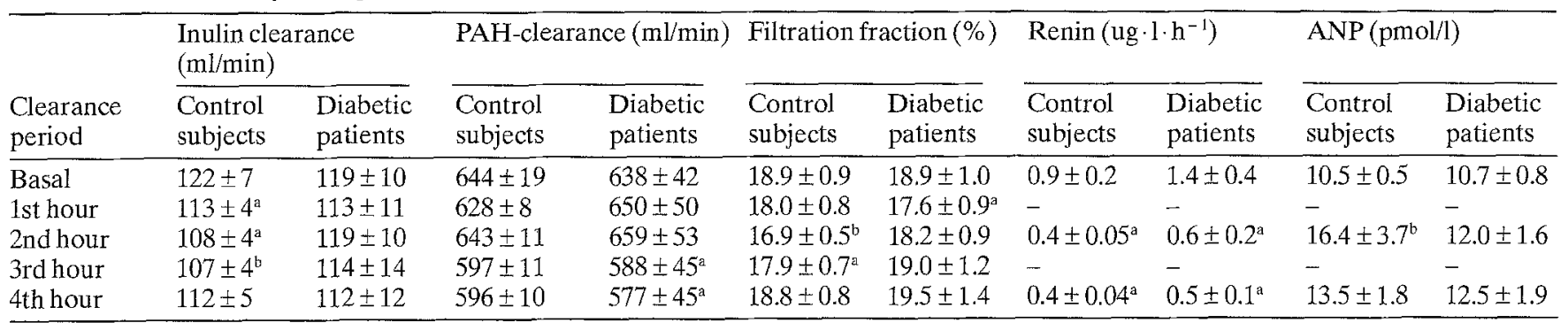

Mean \pm SEM indicated

${ }^{\mathrm{a}} p<0.05$ vs basal; ${ }^{\mathrm{b}} p<0.01$ vs basal

$\mathrm{PAH}=$ para-amino hippuric acid;

$\mathrm{ANP}=$ atrial natriuretic peptide

Table 2. The renal handling of sodium and dopamine in the basal and the 1 st to 4 th hour clearance periods in control and diabetic subjects

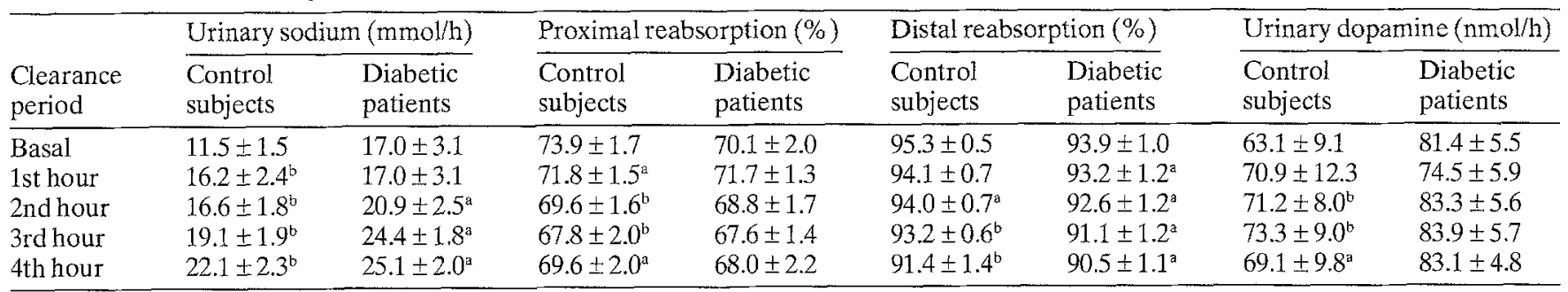

Mean \pm SEM indicated

${ }^{a} p<0.05$ vs basal; ${ }^{\mathrm{b}} p<0.01$ vs basal

Data on the intrarenal handling of sodium and the urinary output of sodium and dopamine in the basal state and in response to $\mathrm{NaCl}$ infusion are presented in Table 2. Basal urinary sodium excretion tended to be higher in the diabetic patients than in the control subjects, although the difference did not attain statistical significance. During the 2 - $\mathrm{h} \mathrm{NaCl}$ infusion sodium excretion increased by $46 \pm 8 \%$ in the control group $(p<0.01)$, whereas in the diabetic group a delayed and less marked $(19 \pm 7 \%)$ increase was observed. Accordingly, the increase in sodium excretion was lower in the diabetic group (Fig. 1).

One and two hours after termination of the $\mathrm{NaCl}$ infusion the cumulative sodium excretion above baseline was still less in the diabetic group. Neither proximal nor distal fractional reabsorption of sodium differed significantly between the diabetic and control groups in the basal state. However, in the control group the fractional proximal tubular reabsorption of sodium (assessed by $\mathrm{C}_{\mathrm{Li}}$ ), decreased immediately following $\mathrm{NaCl}$ infusion $(p<0.01)$, whereas there was no significant decrease in the diabetic group. In both groups there were statistically significant and comparable falls in distal tubular handling of sodium. Baseline urinary excretion of dopamine tended to be greater in the diabetic patients than in the control subjects, although the difference was not statistically significant. There was a marked increase in urinary dopamine excretion during and following $\mathrm{NaCl}$ infusion in the control group (Table 2). In contrast, there was no change in dopamine excretion in the diabetic group. The mean urinary dopamine excretion above baseline was significantly greater in the control group $(8.4 \pm 2.1 \mathrm{nmol} / \mathrm{h})$ than in the diabetic group $(-2.2 \pm 2.1 \mathrm{nmol} / \mathrm{h} ; p<0.01)$. The ratio between urinary excretion of sodium and urinary dopamine (U-Na/U-DA) in the basal state did not differ significantly between the diabetic patients and control subjects $(0.21 \pm 0.04$ and $0.25 \pm 0.06$, respectively). In both groups the ratio increased in a similar way following $\mathrm{NaCl}$ infusion, and the ratio did not differ significantly between the two groups at any time point. Whether calculated for the whole group or for the control and diabetic groups separately, there was no significant correlation between basal sodium excretion and change in sodium or dopamine excretion following $\mathrm{NaCl}$ infusion. There was no significant correlation between the changes in plasma ANP levels and the changes in urinary dopamine output, respectively. Neither was there any significant correlation between plasma insulin levels and urinary dopamine or sodium output at any time point.

\section{Discussion}

Although impaired efficiency in excreting sodium in response to an intravenous sodium load in patients with Type 1 diabetes has been demonstrated in several studies [3-5], the mechanism(s) underlying this abnormality are not well understood. In keeping with recent results by Trevisan et al. [4], the current findings demonstrate that the delayed and blunted acute natriuretic response to $\mathrm{NaCl}$ infusion in diabetic patients is mainly due to impaired inhibition of proximal tubular sodium reabsorption. The results of this study also show for the first time that in diabetic patients the urinary dopamine response to $\mathrm{NaCl}-$ infusion is impaired. In the control subjects $\mathrm{NaCl}$-infusion resulted in a prompt increase in urinary sodium excretion which was paralleled by a corresponding increase in urine dopamine output. In contrast, in the diabetic patients the increase in sodium excretion was markedly delayed and no 


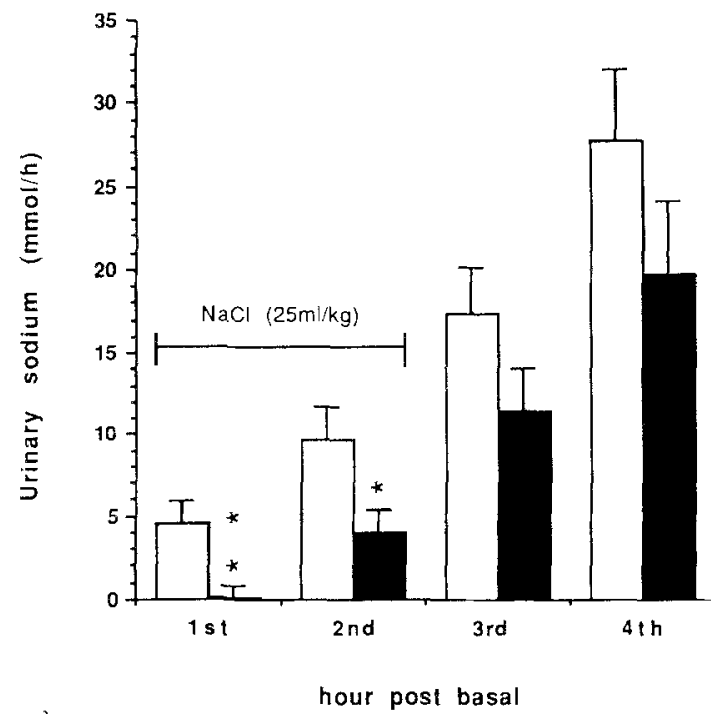

Fig. 1. The cumulative sodium excretion ( $\mathrm{mmol} / \mathrm{h})$ above baseline in control subjects $(\square)$ and patients with diabetes mellitus $(\boldsymbol{\square})$. Vertical bars indicate SEM. ${ }^{*} p<0.05$ and ${ }^{* *} p=0.01$

significant increase in urinary dopamine output was observed. The ratio between urinary excretion of sodium and urine output of dopamine was comparable in the diabetic patients and the control subjects both in the basal state and following $\mathrm{NaCl}$-infusion. This finding, in keeping with results recently presented by Patrick et al. [20], suggests that the relationship between dopamine and sodium excretion is normal in the basal state in diabetic patients and that the blunted acute natriuretic response to $\mathrm{NaCl}$-infusion was associated with impaired dopamine mobilization rather than with attenuated renal tubular sensitivity to dopamine. Taken together these observations suggest that the delayed sodium excretion in Type 1 diabetes may, at least partly, be secondary to attenuated intrarenal dopamine formation and, consequently, impaired inhibition of $\mathrm{Na}^{+}-\mathrm{K}^{+}$ -ATPase activity in the proximal tubule.

To the best of our knowledge, the dopamine response to intravenous or oral salt loading has not previously been studied in diabetic patients. The mechanism(s) causing the attenuated dopamine response to $\mathrm{NaCl}$-infusion in the diabetic patients are not clear. All subjects were normoglycaemic at the start of $\mathrm{NaCl}$-infusion and blood glucose remained constant throughout the $4 \mathrm{~h}$ observation period. Consequently hyperglycaemia cannot explain the abnormal mobilization of dopamine in the diabetic patients. Baseline output of dopamine and sodium tended to be higher in the diabetic group as compared with the control group. Although the differences between the two groups did not reach statistical significance the data may suggest a higher dietary sodium intake in the diabetic group. Conceivably, higher dietary sodium intake might then have impaired the ability to acutely increase dopamine formation and sodium excretion in response to $\mathrm{NaCl}$-infusion in a comparable way to the control subjects. However, the lack of any correlation between basal sodium or dopamine excretion with either the changes in urinary output of sodium or dopamine excretion following $\mathrm{NaCl}$-infusion renders this possibility unlikely. It has been reported that lithium carbonate used for the assessment of $\mathrm{C}_{\mathrm{Li}}$ reduces cumulative sodium excretion by up to $40 \%$ [21]. Whether lithium carbonate influences dopamine excretion is not known. Whilst such an effect cannot be excluded, it is unlikely that an effect of lithium contributed to the difference in dopamine response, since both groups received the same amount of lithium.

Since circulating insulin levels were higher in the diabetic patients than in the control subjects, a suppressive effect of insulin on renal dopamine formation is another possible explanation for the attenuated dopamine formation and sodium excretion in the diabetic group. Indeed, several studies have demonstrated that insulin exerts an antinatriuretic effect in the kidney [4,7-9]. However, the antinatriuretic site of action of insulin within the kidney is controversial. By micropuncture technique De Fronzo et al. [7] located the acute antinatriuretic effect of insulin mainly to the distal tubule. Using the euglycaemic insulin clamp technique and lithium clearance determination, Skøtt et al. [8] studied the effect of insulin on renal sodium handling in healthy subjects. Their results demonstrate that physiological elevation of plasma insulin levels causes sodium retention by stimulating distal tubular reabsorption of sodium. However, in conflict with these results, observations by Trevisan et al. [4] imply that hyperinsulinaemia leads to increased proximal sodium reabsorption. In addition the results showed that hyperinsulinaemia causes attenuated inhibition of proximal tubular sodium reabsorption in response to volume expansion by $\mathrm{NaCl}$. Brimble et al. [22], however, did not observe an antinatriuretic effect of hyperinsulinaemia in subjects in whom central blood volume was increased during water immersion. In view of these results, although conflicting, we cannot exclude the possibility that in our diabetic patients hyperinsulinaemia may have contributed to the impaired acute natriuretic response to $\mathrm{NaCl}$-infusion. If this were the case, since insulin may stimulate [23] and dopamine inhibits [12] tubular $\mathrm{Na}^{+}-\mathrm{K}^{+}$-ATPase activity, one might speculate that the stimulatory action of insulin on sodium reabsorption in the proximal tubule may, at least partly, be mediated by inhibition of dopamine formation. However, further studies are needed to test the validity of this hypothesis.

Acute volume expansion is a powerful stimulus for the release of ANP from the atria [24] and it has been documented that ANP contributes to the natriuretic response to volume expansion $[25,26]$. In the present study $\mathrm{NaCl}$ administration resulted in significantly increased plasma ANP levels in the control subjects, whereas no significant changes were observed in the diabetic patients. Sodium handling and plasma ANP concentrations in response to $\mathrm{NaCl}$-infusion were also recently investigated in normotensive patients with Type 1 diabetes by Trevisan et al. [4]. In agreement with our findings they observed an attenuated ANP response in diabetic subjects. Conceivably therefore, the impaired ANP response may also have contributed to the attenuated sodium excretion in the diabetic patients. Many of the physiological effects of ANP such as natriuresis, diuresis, vasodilation and inhibition of the renin-aldosterone system are shared by dopamine and it has been suggested that the renal effect of ANP may, at least partly, be mediated by dopamine [27]. In rats dop- 
amine receptor antagonists has been shown to attenuate the natriuresis and diuresis stimulated by exogenous ANP [27-30]. In man, however, inhibition of dopamine production by inhibition of dopa-decarboxylase using carbidopa does not seem to affect the renal natriuretic response to ANP. This implies that in humans the renal effects of ANP are not mediated by dopamine [31]. The lack of any correlation between the rise in ANP and urinary output of dopamine in the present study also argues against ANP acting through intrarenal dopamine to cause natriuresis.

In summary, this study confirms previous results showing that patients with Type 1 diabetes have a blunted excretion of sodium in response to an acute $\mathrm{NaCl}$-load. This abnormality seems mainly to be due to impaired inhibition of proximal tubular sodium reabsorption, which may, at least partly, be the result of defective intrarenal dopamine mobilisation.

Acknowledgements. We thank Ms. E. Digreus and Ms. U.Petterson for their help with the clearance studies and Ms. A.-M. Forsberg and Ms. E. Nilsson for analysis of lithium. This study was supported by grants from the Swedish Medical Society, Swedish Hoechst Diabetic Foundation, the Swedish Diabetic Association and Smith Klein \& French AB, Stockholm, Sweden.

\section{References}

1. Feldt-Rasmussen B, Mathiesen ER, Deckert T, Christensen NJ, Bent-Hansen L, Nielsen MD (1987) Central role for sodium in the pathogenesis of blood pressure changes independent of angiotensin, aldosterone and cathecolamines in Type 1 (insulindependent) diabetes mellitus. Diabetologia 30: 610-617

2. O'Hare JA, Ferriss JB, Brady D, Twomey B, O'Sullivan DJ (1985) Exchangeable sodium and renin in hypertensive diabetic patients with and without nephropathy. Hypertension 7 [Suppl 2]: 43-48

3. Roland JM, O'Hare JP, Walters G, Corrall RJM (1986) Sodium retention in response to saline infusion in uncomplicated diabetes mellitus. Diabetes Res 3:213-215

4. Trevisan R, Fioretti P, Semplicini A et al. (1990) Role of insulin and atrial natriuretic peptide in sodium retention in insulintreated IDDM patients during isotonic volume expansion. Diabetes 39:289-298

5. Semplicini A, Angeli P, Nosadini R et al. (1989) Tubular $\mathrm{Na}+$ handling in type 1 insulin-dependent diabetics during saline and ketone body infusion. Diabetes Res 11: 67-72

6. O'Hare JP, Roland JM, Walters G, Corrall RJM (1986) Impaired sodium excretion in response to volume expansion induced by water immersion in insulin-dependent diabetes mellitus. Clin Sci 71: $403-409$

7. DeFronzo RA, Cooke CR, Andres R, Faloona GR, Davis PJ (1975) The effect of insulin on renal handling of sodium, potassium, calcium and phosphate in man. J Clin Invest 55: 845-855

8. Skøtt P, Hother-Nielsen O, Bruun NE, Giese J, Nielsen MD, Beck-Nielsen H, Parving HH (1989) Effects of insulin on kidney function and sodium excretion in healthy subjects. Diabetologia 32: 694-699

9. Baum M (1987) Insulin stimulates volume absorption in the rabbit proximal convoluted tubule. J Clin Invest 79: 1104-1109

10. Lee MR (1986) Dopamine and the kidney. In: Lote CT (ed) Advances in renal physiology. Croom Helm, London Sydney. pp 218-246

11. Goldstein M, Fuxe K, Hökfelt T (1972) Characterisation and tissue localisation of catecholamine-synthesising enzymes. Pharmacol Rev 24: 293-308

12. Aperia A, Bertorello A, Seri I (1987) Dopamine causes inhibition of $\mathrm{Na}^{+}-\mathrm{K}^{+}$-ATPase activity in rat proximal convoluted tubule segments. Am J Physiol 252: F39-F45
13. Zimlichman R, Levinson PD, Kelly G, Stull R, Keiser HR, Goldstein DS (1988) Derivation of urinary dopamine from plasma dopa. Clin Sci 75: 515-520

14. Thomsen K (1984) Lithium clearance: a new method for determining proximal and distal tubular reabsorption of sodium and water. Nephron 37:217-223

15. Riggin RM, Kissinger PT (1977) Determination of catecholamines in urine by reversed-phase liquid chromatography with electrochemical detection. Analytical Chem 49:2109-2111

16. Keller R, Oke A, Mefford I, Adams RN (1976) Liquid chromatographic analysis of catecholamines. Routine assay for regional brain mapping. Life Sci 19: 995-1004

17. Andersson U, Sylvén C, Lindvall K, Theodorsson E, Norée L-O (1988) Cardiac function and cardiovascular hormone balance during hemodialysis with special reference to atrial natriuretic peptide. Clin Nephrol 30: 303-307

18. Wide L, Axén R, Porath J (1967) Radioimmunosorbent assay for proteins chemical couplings of antibodies to insoluble dextran. Immunochemistry 4: 381-386

19. Amidsen A (1975) The estimation of lithium in urine, In: Johnson FN (ed) Lithium Research and Therapy. Academic Press, London, pp 181-195

20. Patrick AW, Jeffrey RF, Collier A, Clarke, Lee MR (1990) Relationship between urinary excretion of sodium and dopamine in type 1 diabetic patients with and without microalbuminuria. Diabetic Med 7:53-56

21. Jeffrey RF, MacDonald TM, Freestone S, Lee MR (1989) The effect of carbidopa and lithium on the systemic and renal response to acute intravenous saline loading in normal man. Nephrol Dial Transplant 4: 271-277

22. Brimble A, Corrall RJM, Mattocks J, O'Hare JP, Roland JM (1985) Insulin and the renal response to volume expansion in man. J Physiol (London) 364: 66P

23. Moore RD (1983) Effect of insulin upon ion transport. Biochem Biophys Acta 737: 1-49

24. Sagnella GA, Markandu ND, Shore AC, MacGregor GA (1985) Effects of changes in dietary sodium intake and saline infusion on immunoreactive atrial natriuretic peptide in human plasma. Lancet II: 1208-1210

25. Mimran A, Nussberger J, Ribstein J, Waeber B, Brunner HR (1988) Response of atrial natriuretic peptide to acute saline loading in essential hypertension. Am J Physiol 255: F1085-F1090

26. Naruse M, Obana K, Naruse K, Sugino N, Demura H, Shizume $\mathrm{K}$, Inagami T (1985) Antisera to atrial natriuretic factor reduces urinary sodium excretion and increases plasma renin activity in rats. Biochem Biophys Commun 132: 954-960

27. Hansell P, Fasching A, Sjöquist M, Andén N-E, Ulfendahl HR (1987) The dopamine receptor antagonist haloperidol blocks natriuretic but not hypotensive effects of the atrial natriuretic factor. Acta Physiol Scand 130: 401-407

28. Marin-Grez M, Briggs JP, Schubert G, Schnermann J (1985) Dopamine receptor antagonists inhibit the natriuretic response to atrial natriuretic factor (ANF). Life Sci 36: 2171-2176

29. Petterson A, Hedner J, Hedner T (1986) The diuretic effect of atrial natriuretic peptide (ANP) is dependent on dopaminergic activation. Acta Phys Scand 126: 619-621

30. Webb RL, Della Pucca R, Manniello J, Robson RD, Zimmerman MB, Ghai RD (1986) Dopaminergic mediation of the diuretic and natriuretic effects of ANF in the rat. Life Sci 38: 2319-2327

31. Lewis HL, Wilkins MR, Kendall MJ, Lee MR (1989) Carbidopa does not affect the renal response to atrial natriuretic factor in man. Clin Sci 77:281-285

Received: 2 May 1990

and in revised form: 18 September 1990

Dr. A. Alvestrand

Department of Renal Medicine

Huddinge University Hospital, K56

S-14186 Huddinge

Sweden 